\title{
Systematic Study on Morphological, Electrochemical Impedance and Electrocatalytic Activity of Graphitic Carbon Nitride Modified on Glassy Carbon Substrate from Sequential Exfoliation in Water
}

\author{
Veeramani Mangala Gowri, Ajay Ajith and S. Abraham John* \\ Centre for Nanoscience and Nanotechnology, Department of Chemistry \\ The Gandhigram Rural Institute (Deemed to be University) \\ Gandhigram-624 302, Dindigul, Tamilnadu, India
}

*Corresponding author: Tel: +919443504981; Fax:+914512453031
E-mail: abrajohn@yahoo.co.in; $\underline{\text { s.abrahamjohn@,ruraluniv.ac.in }}$

Number of Pages: 19

Number of Figures: 12

Number of Tables: 3 


\section{List of contents}

Chemicals and Instrumentation: Chemicals and instrumentation used in the present study were described.

Figure S1. (A) UV-Visible and (B) emission spectra of dispersed solution of GCN in water after 120 min exfoliation. Inset: Photographs of GCN under (A) room light and (B) UV light.

Figure S2. Photographs of (a) bulk GCN and (b) the same after $12 \mathrm{~h}$ sonication in water. Tyndall effect by the corresponding solutions (c) and (d) under red laser light.

Figure S3. (A) FT-IR spectrum of GCN powder. (B) Expanded region from 500-2000 $\mathrm{cm}^{-1}$.

Figure S4. XPS of (A) C1s and (B) N1s regions for powder GCN.

Figure S5. ATR-FT-IR spectra of (A) GCN coated on GC plate after (a) 15, (b) 30, (c) 60, (d) 120 and (e) 180 min exfoliation in water. (B) Expanded region from 500-2000 $\mathrm{cm}^{-1}$.

Figure S6. CVs obtained for (a) bare GC and GCN coated on GC electrodes from (b) 15, (c) 60, (d) 90, (e) 120 and (f) 150 min exfoliation in $1 \mathrm{mM} \mathrm{K}_{3}\left[\mathrm{Fe}(\mathrm{CN})_{6}\right] / \mathrm{K}_{4}\left[\mathrm{Fe}(\mathrm{CN})_{6}\right]$ containing $0.1 \mathrm{M} \mathrm{KCl}$ at a scan rate of $50 \mathrm{mV} / \mathrm{s}$.

Figure S7. Nyquist plots for (a) supernatant solution of centrifuged GCN (120 min exfoliation) modified on GC electrode and (b) GCN modified on GC electrode from 720 min exfoliation in $1 \mathrm{mM} \mathrm{K}_{3}\left[\mathrm{Fe}(\mathrm{CN})_{6}\right] / \mathrm{K}_{4}\left[\mathrm{Fe}(\mathrm{CN})_{6}\right]$ containing $0.1 \mathrm{M} \mathrm{KCl}$ at scanning frequencies from 0.01 to $100,000 \mathrm{~Hz}$. Inset: Randles circuit model.

Figure S8. Bode amplitude plots for (a) bare GC and GCN coated on GC electrodes from (b) 15, (c) 30, (d) 60, (e) 90, (f) 120, (g) 150 and (h) 180 min exfoliation in $1 \mathrm{mM}$ 
$\mathrm{K}_{3}\left[\mathrm{Fe}(\mathrm{CN})_{6}\right] / \mathrm{K}_{4}\left[\mathrm{Fe}(\mathrm{CN})_{6}\right]$ containing $0.1 \mathrm{M} \mathrm{KCl}$ at scanning frequencies from 0.01 to $100,000 \mathrm{~Hz}$.

Figure S9. Bode-phase angle plots for (a) bare GC and GCN coated on GC electrodes from (b) 15, (c) 30, (d) 60, (e) 90, (f) 120, (g) 150 and (h) 180 min exfoliation in $1 \mathrm{mM}$ $\mathrm{K}_{3}\left[\mathrm{Fe}(\mathrm{CN})_{6}\right] / \mathrm{K}_{4}\left[\mathrm{Fe}(\mathrm{CN})_{6}\right]$ containing $0.1 \mathrm{M} \mathrm{KCl}$ at scanning frequencies from 0.01 to $100,000 \mathrm{~Hz}$.

Figure S10. CVs obtained for $1 \mathrm{mM}$ AA at (b) GCN modified on GC electrode from 720 min exfoliation and (c) supernatant solution of GCN (after centrifugation) coated on GC electrode

Figure S11. CVs obtained for $1 \mathrm{mM}$ (A) DA and (B) HP at (b) supernatant solution of centrifuged GCN (120 min exfoliation) modified on GC electrode in $0.2 \mathrm{M} \mathrm{PB}$ solution ( $\mathrm{pH}$ 7.2) at a scan rate of $50 \mathrm{mV} \mathrm{s}^{-1}$. (a) Supernatant solution of centrifuged GCN (120 min exfoliation) modified on GC electrode in the absence of (A) DA and (B) HP.

Figure S12. (A) CVs recorded for the oxidation of $1 \mathrm{mM}$ of AA at GC electrode modified with GCN (120 min exfoliation) in 0.2 M PB solution $\mathrm{pH}(7.2)$ at different cycles after (a) $1^{\text {st }}$ and (b) $10^{\text {th }}$ cycles. (B) Chronoamperometric $i$ - $t$ curve for GC electrode modified with GCN (120 min exfoliation) in $0.2 \mathrm{M}$ PB solution ( $\mathrm{pH} 7.2)$.

Table S1. FT-IR and ATR-FT-IR spectral data of powder GCN and GCN coated on GC plates with different exfoliation time.

Table S2. The XPS peaks for GCN powder and GCN coated on GC plate after exfoliation in water for $120 \mathrm{~min}$ and their assignments.

Table S3. The electroactive surface area, charge transfer resistance and heterogeneous electron transfer rate constant obtained for bare GC and GCN coated on GC electrode from different exfoliation time. 


\section{Chemicals}

Urea (U), hydrogen peroxide (HP), dopamine (DA), ascorbic acid (AA), sulfuric acid $\left(\mathrm{H}_{2} \mathrm{SO}_{4}\right)$, sodium dihydrogen phosphate dihydrate $\left(\mathrm{NaH}_{2} \mathrm{PO}_{4} \cdot 2 \mathrm{H}_{2} \mathrm{O}\right)$ and disodium hydrogen phosphate dihydrate $\left(\mathrm{Na}_{2} \mathrm{HPO}_{4} \cdot 2 \mathrm{H}_{2} \mathrm{O}\right)$ were purchased from Merck, India and were used as received. Glassy carbon (GC) plates were purchased from Alfa-Aesar. $\mathrm{Na}_{2} \mathrm{HPO}_{4}$ and $\mathrm{Na}_{2} \mathrm{H}_{2} \mathrm{PO}_{4}$ were used to prepare phosphate buffer (PB) solution ( $\mathrm{pH}$ 7.2). Double distilled water was used to prepare the solutions used in the present work.

\section{Instrumentation}

Absorption spectra were measured using JASCO V-750 UV-visible spectrophotometer. Emission and excitation spectra were performed on a JASCO-FP-8500 spectrofluorimeter. The FT-IR measurements were carried out in JASCO FT-IR-460 plus model. High resolution transmission electron microscopy (HR-TEM) images were taken from JEOL JEM 2100, USA operating at $200 \mathrm{kV}$. XPS measurements were done by using PHI 5000 VERSAPROBE scanning ESCA Microscope. Rigaku X-ray diffraction unit using Nifiltered $\mathrm{Cu} \mathrm{K \alpha}(\lambda=1.5406 \AA)$ radiation was used for XRD measurements whereas CHI model 643B (Austin, TX, USA) electrochemical analyzer was used for electrochemical measurements. Scanning electron microscope (SEM) measurements were carried at VEGA3 TESCAN, USA. For ATR-FT-IR, XRD, XPS and SEM analysis GC plate was used as a substrate. 

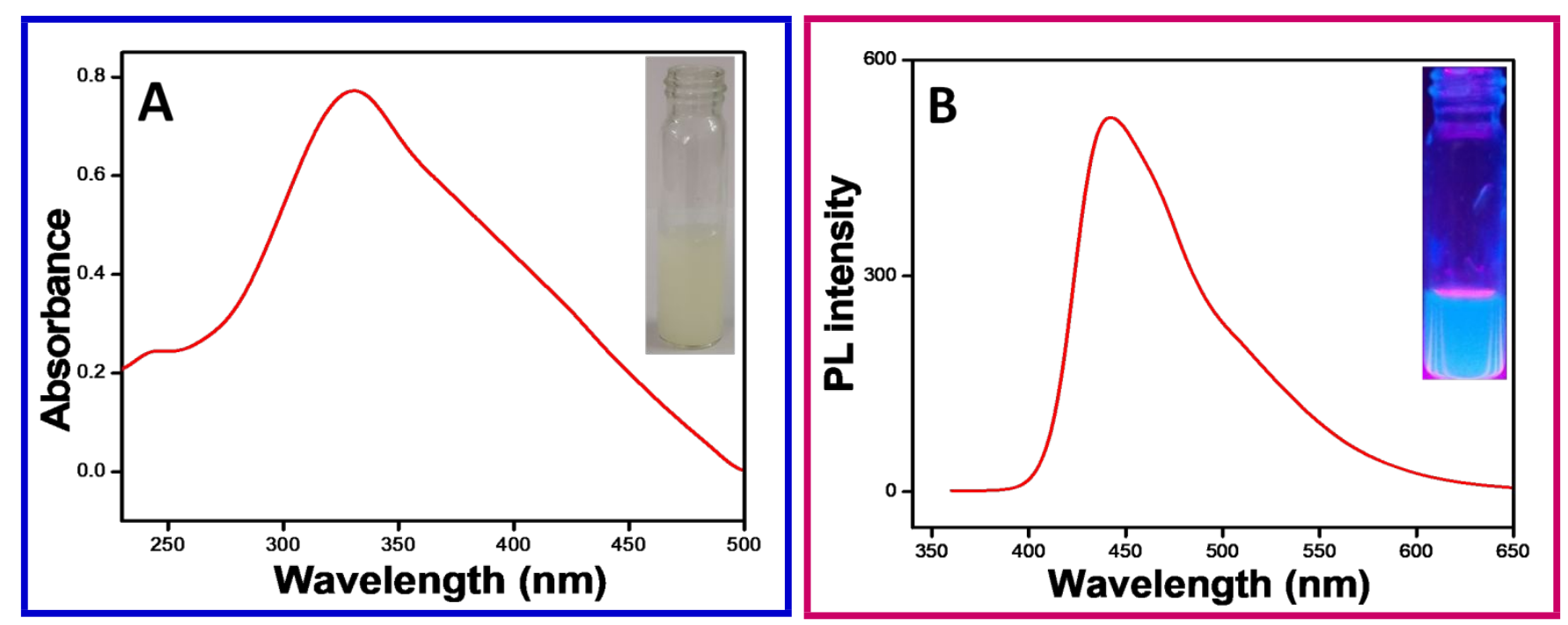

Figure S1. (A) UV-Visible and (B) emission spectra of dispersed solution of GCN in water after 120 min exfoliation. Inset: Photographs of GCN under (A) room light and (B) UV light. 


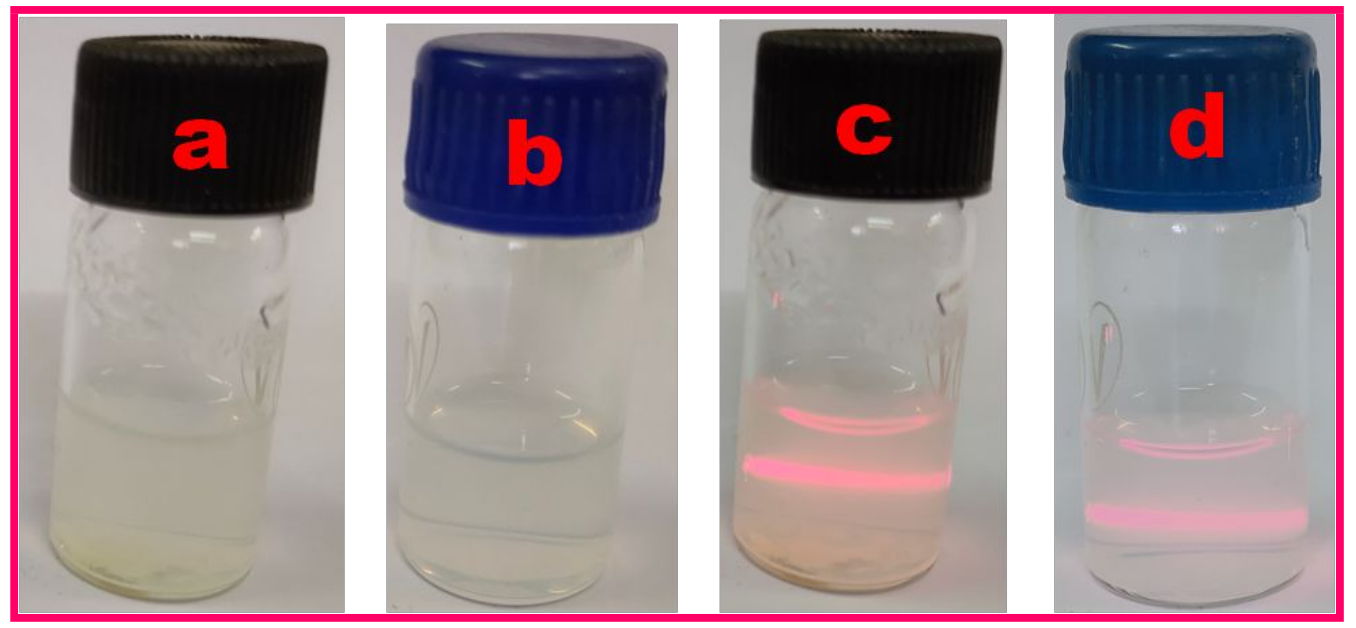

Figure S2. Photographs of (a) bulk GCN and (b) the same after $12 \mathrm{~h}$ sonication in water.

Tyndall effect by the corresponding solutions (c) and (d) under red laser light. 

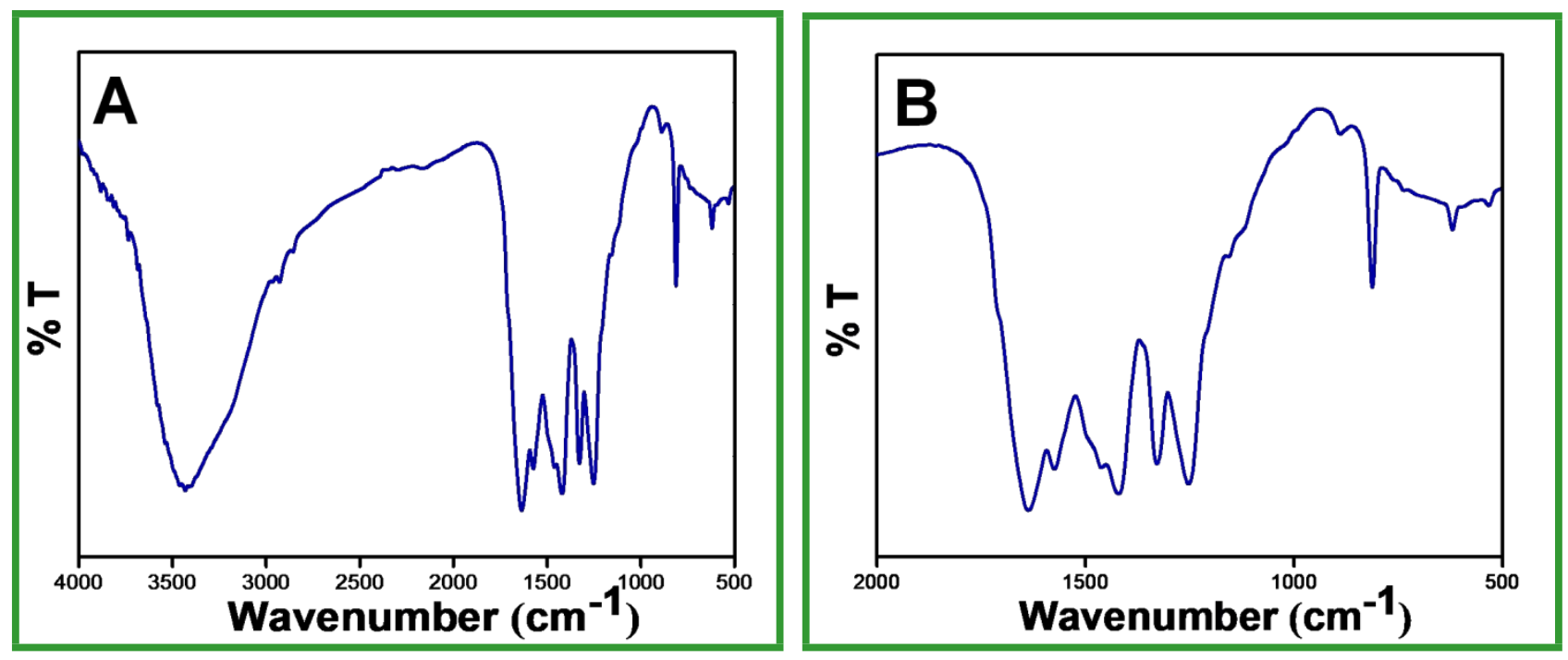

Figure S3. (A) FT-IR spectrum of GCN powder. (B) Expanded region from 500-2000 $\mathrm{cm}^{-1}$. 

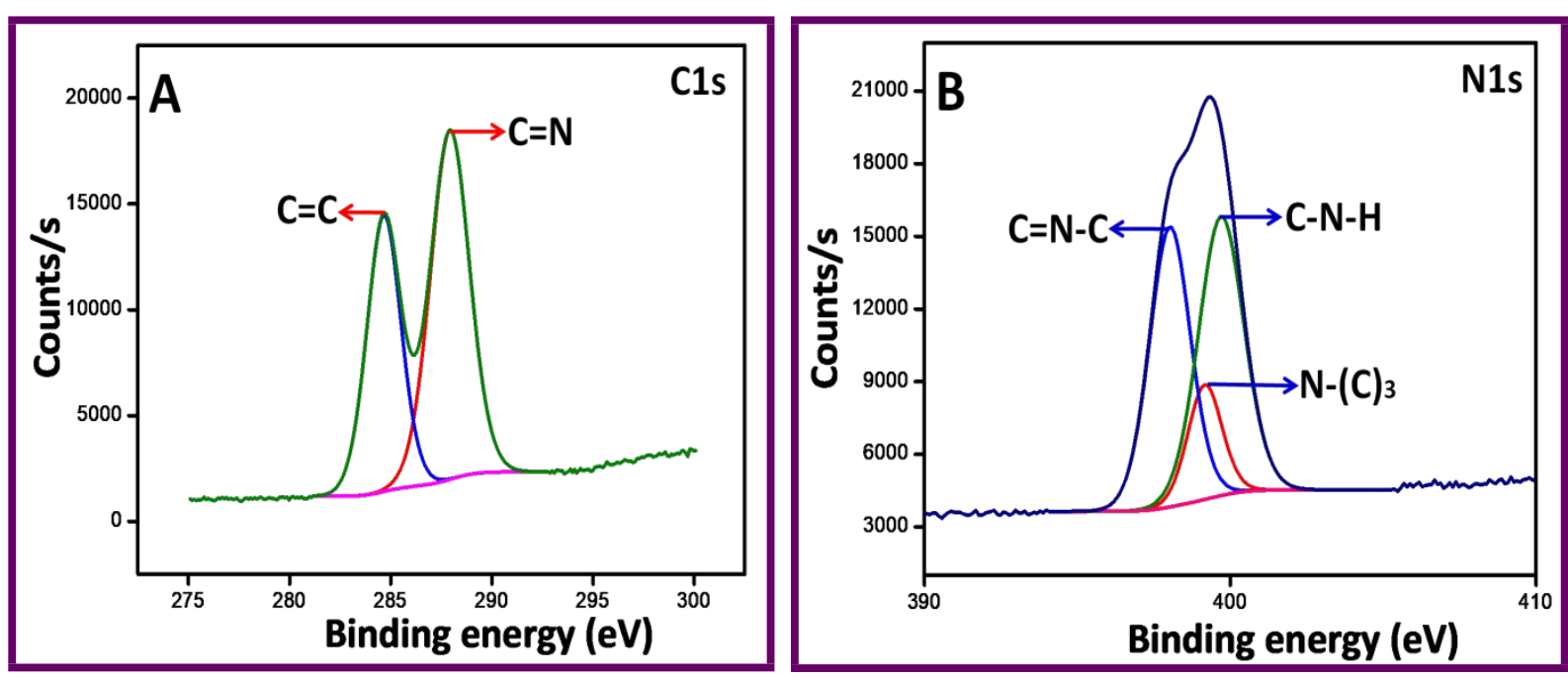

Figure S4. XPS of (A) C1s and (B) N1s regions for powder GCN. 

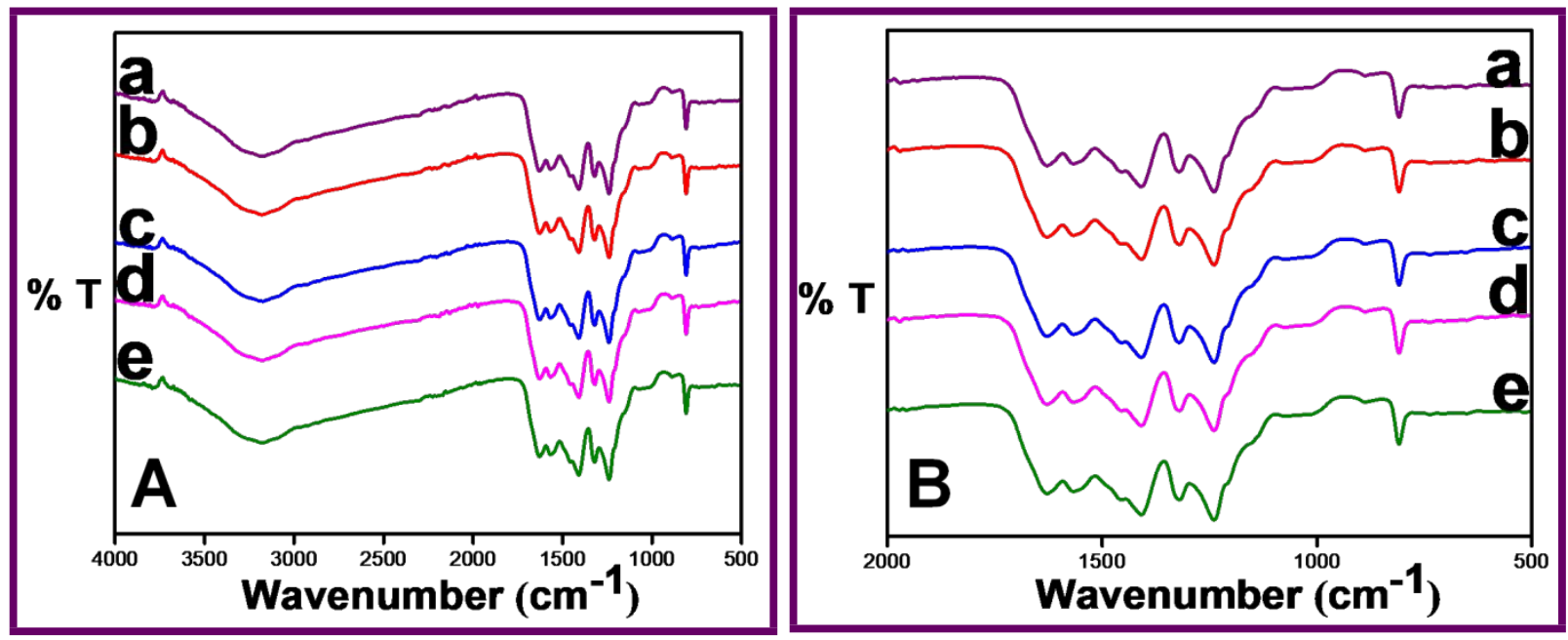

Figure S5. ATR-FT-IR spectra of (A) GCN coated on GC plate after (a) 15, (b) 30, (c) 60, (d) 120 and (e) 180 min exfoliation in water. (B) Expanded region from 500-2000 $\mathrm{cm}^{-1}$. 


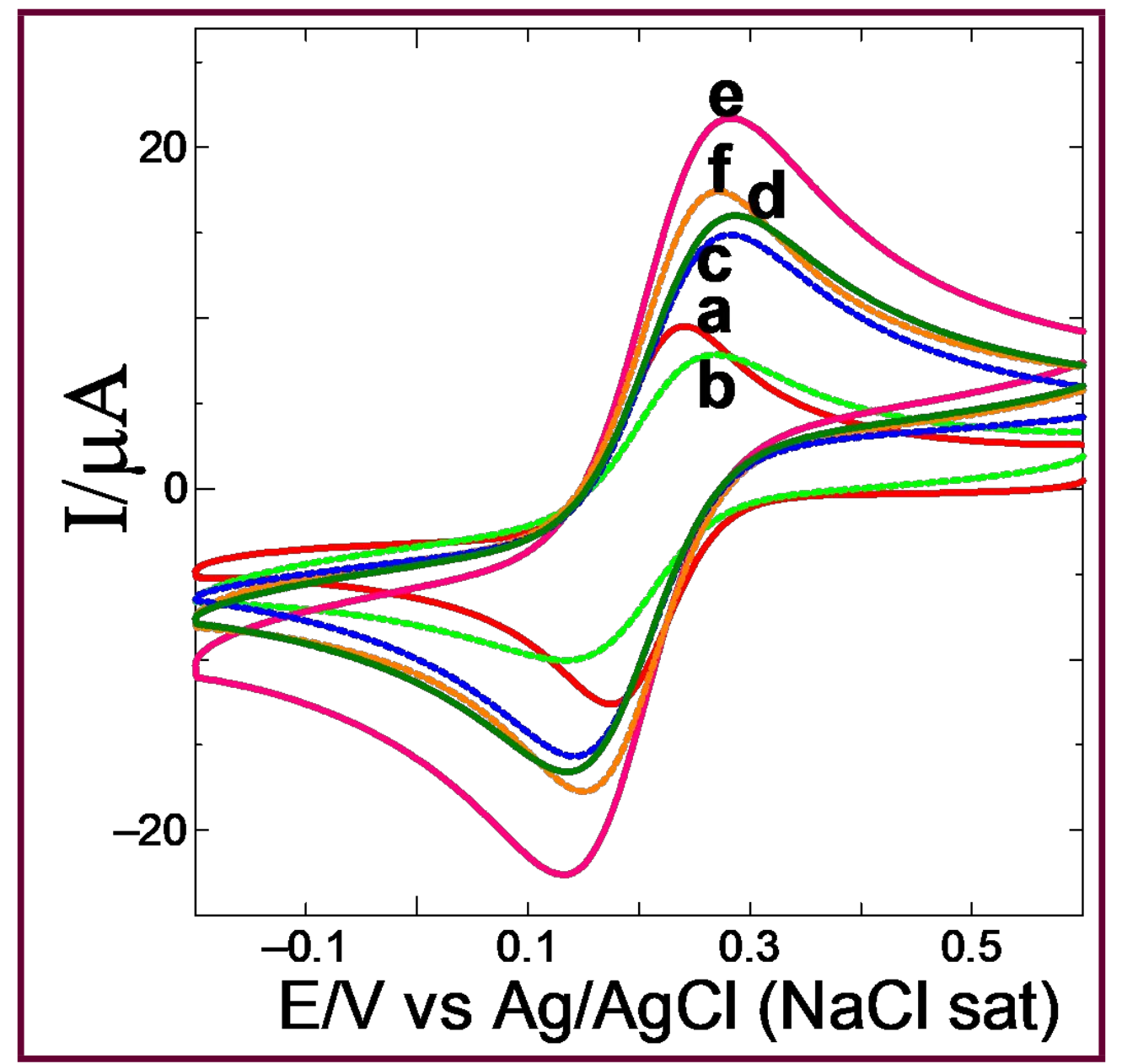

Figure S6. CVs obtained for (a) bare GC and GCN coated on GC electrodes from (b) 15, (c) 60, (d) 90, (e) 120 and (f) 150 min exfoliation in $1 \mathrm{mM} \mathrm{K}_{3}\left[\mathrm{Fe}(\mathrm{CN})_{6}\right] / \mathrm{K}_{4}\left[\mathrm{Fe}(\mathrm{CN})_{6}\right]$ containing $0.1 \mathrm{M} \mathrm{KCl}$ at a scan rate of $50 \mathrm{mV} / \mathrm{s}$. 


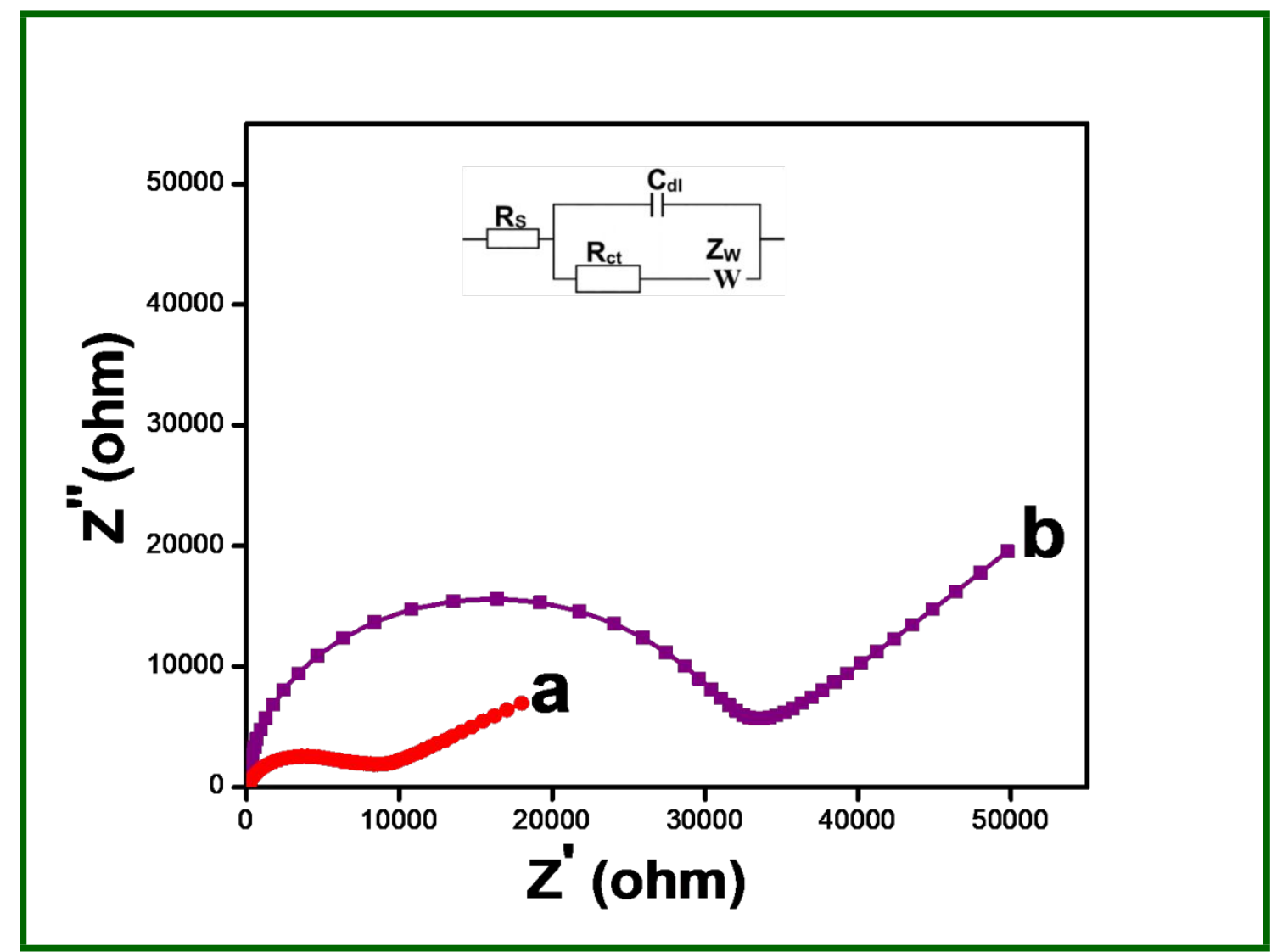

Figure S7. Nyquist plots for (a) supernatant solution of centrifuged GCN (120 min exfoliation) modified on GC electrode and (b) GCN modified on GC electrode from 720 min exfoliation in $1 \mathrm{mM} \mathrm{K}_{3}\left[\mathrm{Fe}(\mathrm{CN})_{6}\right] / \mathrm{K}_{4}\left[\mathrm{Fe}(\mathrm{CN})_{6}\right]$ containing $0.1 \mathrm{M} \mathrm{KCl}$ at scanning frequencies from 0.01 to $100,000 \mathrm{~Hz}$. Inset: Randles circuit model. 


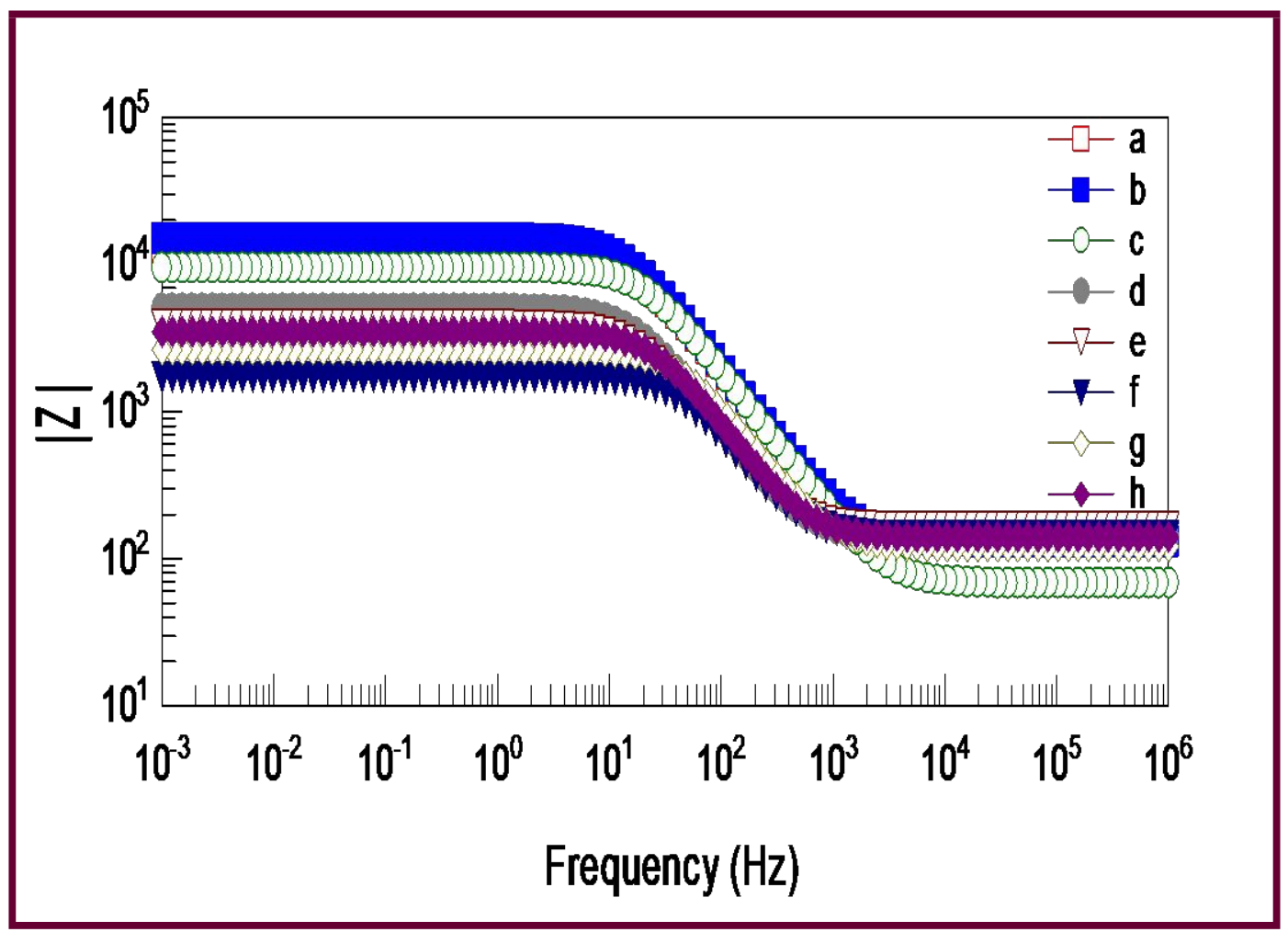

Figure S8. Bode amplitude plots for (a) bare GC and GCN coated on GC electrodes from (b) 15, (c) 30, (d) 60, (e) 90, (f) 120, (g) 150 and (h) 180 min exfoliation in $1 \mathrm{mM}$ $\mathrm{K}_{3}\left[\mathrm{Fe}(\mathrm{CN})_{6}\right] / \mathrm{K}_{4}\left[\mathrm{Fe}(\mathrm{CN})_{6}\right]$ containing $0.1 \mathrm{M} \mathrm{KCl}$ at scanning frequencies from 0.01 to $100,000 \mathrm{~Hz}$. 


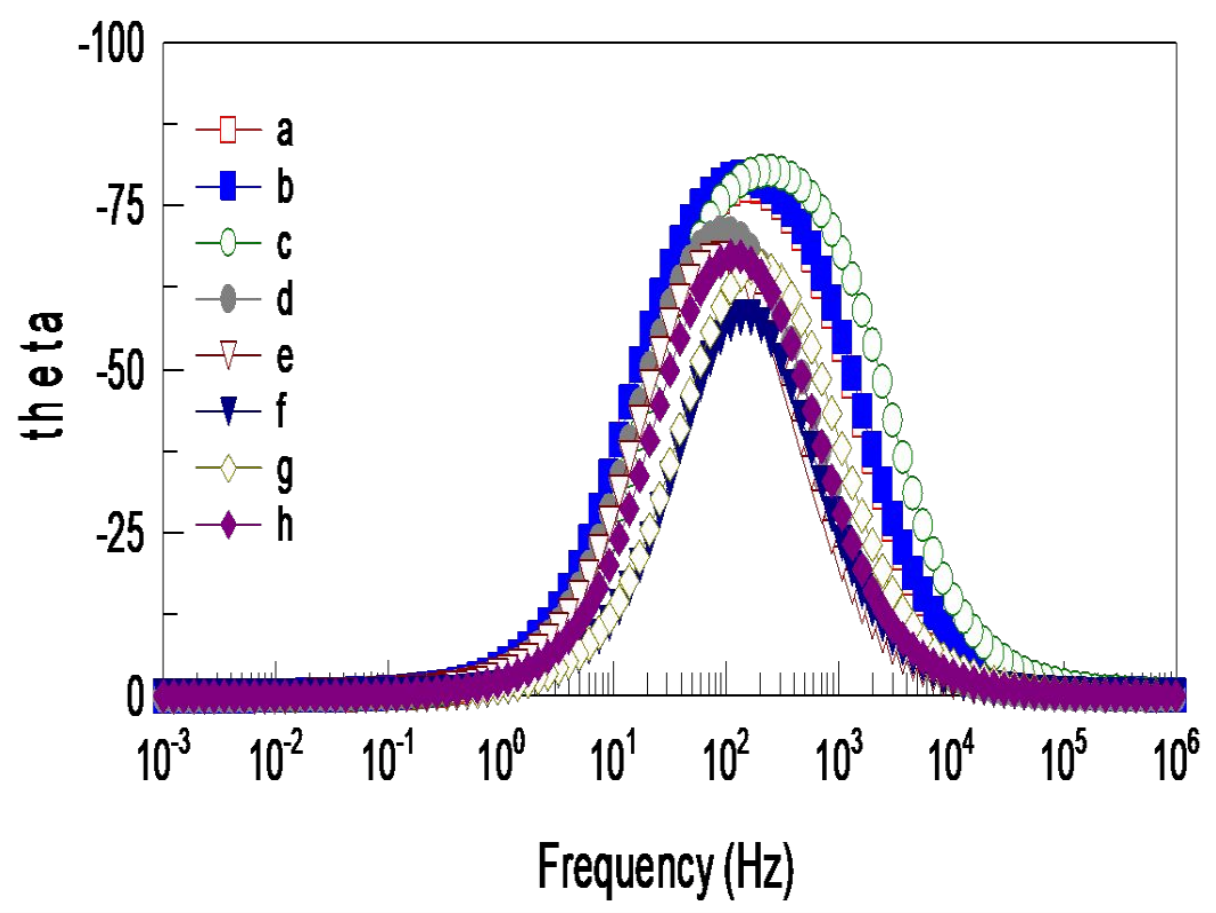

Figure S9. Bode-phase angle plots for (a) bare GC and GCN coated on GC electrodes from (b) 15 , (c) 30, (d) 60, (e) 90, (f) 120, (g) 150 and (h) 180 min exfoliation in $1 \mathrm{mM}$ $\mathrm{K}_{3}\left[\mathrm{Fe}(\mathrm{CN})_{6}\right] / \mathrm{K}_{4}\left[\mathrm{Fe}(\mathrm{CN})_{6}\right]$ containing $0.1 \mathrm{M} \mathrm{KCl}$ at scanning frequencies from 0.01 to $100,000 \mathrm{~Hz}$. 


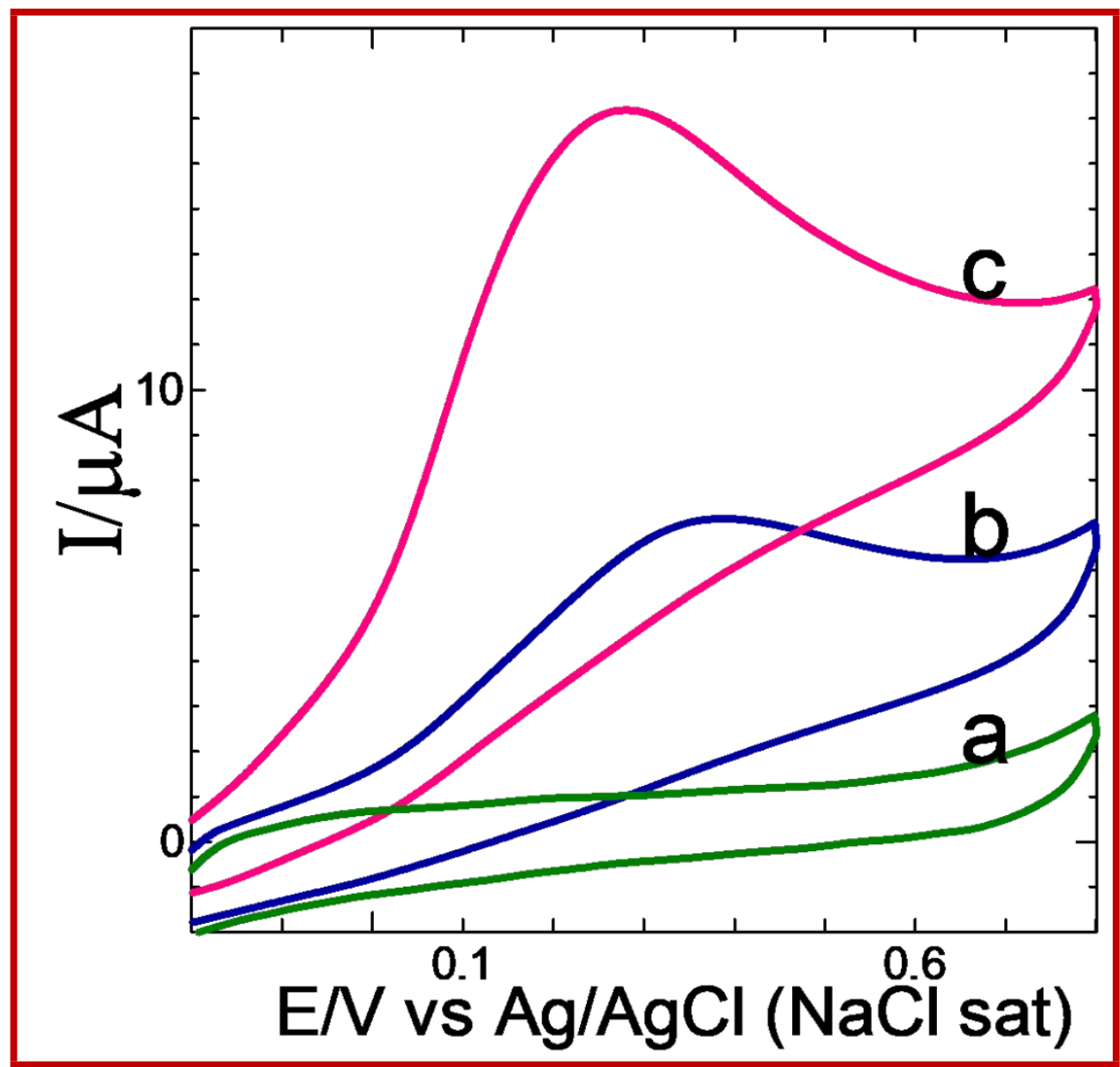

Figure S10. CVs obtained for $1 \mathrm{mM} \mathrm{AA}$ at (b) GCN modified on GC electrode from $720 \mathrm{~min}$ exfoliation and (c) supernatant solution of GCN (after centrifugation) coated on GC electrode containing 0.2 M PB solution ( $\mathrm{pH} 7.2$ ) at a scan rate of $50 \mathrm{mV} \mathrm{s}^{-1}$. (a) Supernatant solution of 120 min exfoliated GCN coated on GC electrode in the absence of AA. 

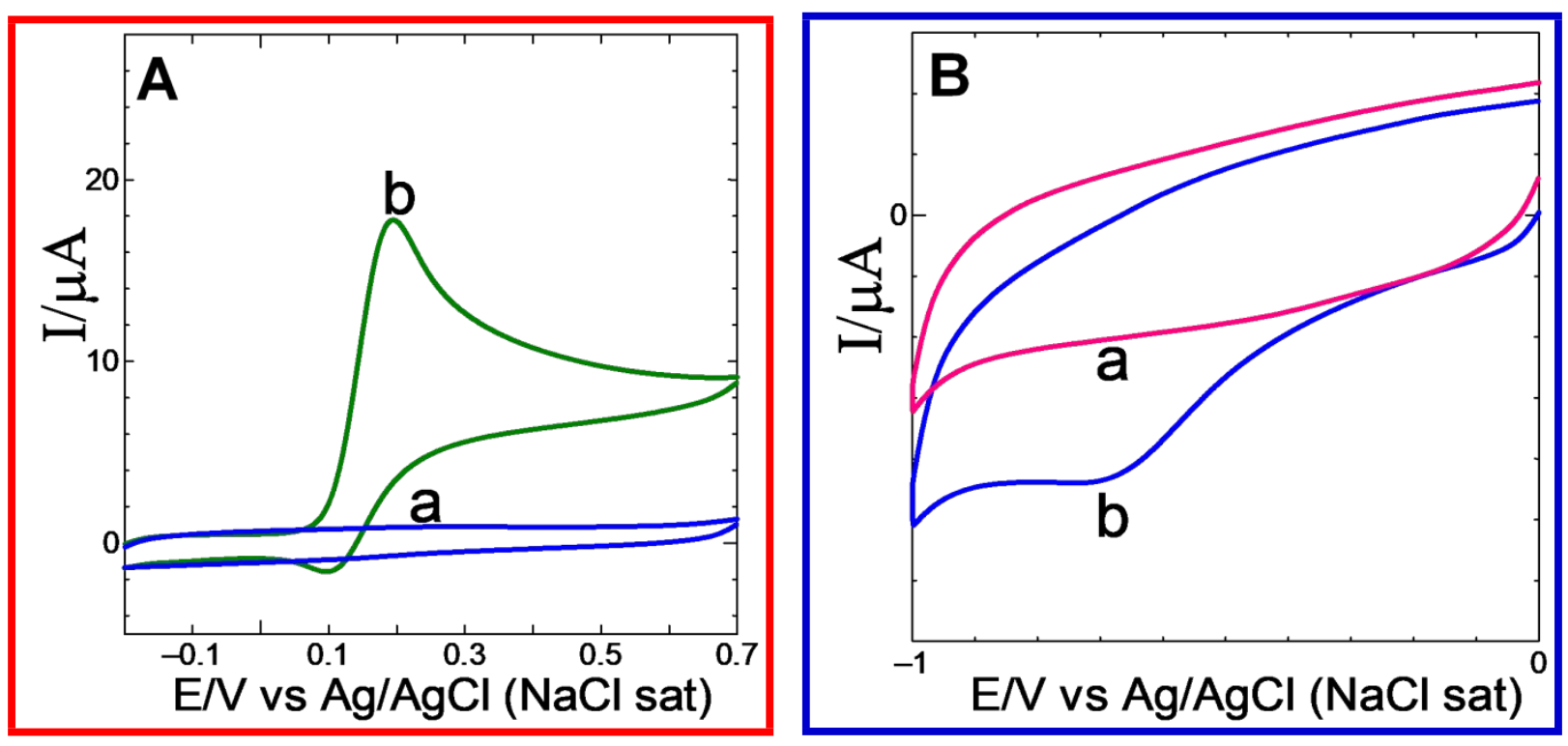

Figure S11. CVs obtained for $1 \mathrm{mM}$ (A) DA and (B) HP at (b) supernatant solution of centrifuged GCN (120 min exfoliation) modified on GC electrode in $0.2 \mathrm{M} \mathrm{PB}$ solution ( $\mathrm{pH}$ 7.2) at a scan rate of $50 \mathrm{mV} \mathrm{s}^{-1}$. (a) Supernatant solution of centrifuged GCN (120 min exfoliation) modified on GC electrode in the absence of (A) DA and (B) HP. 

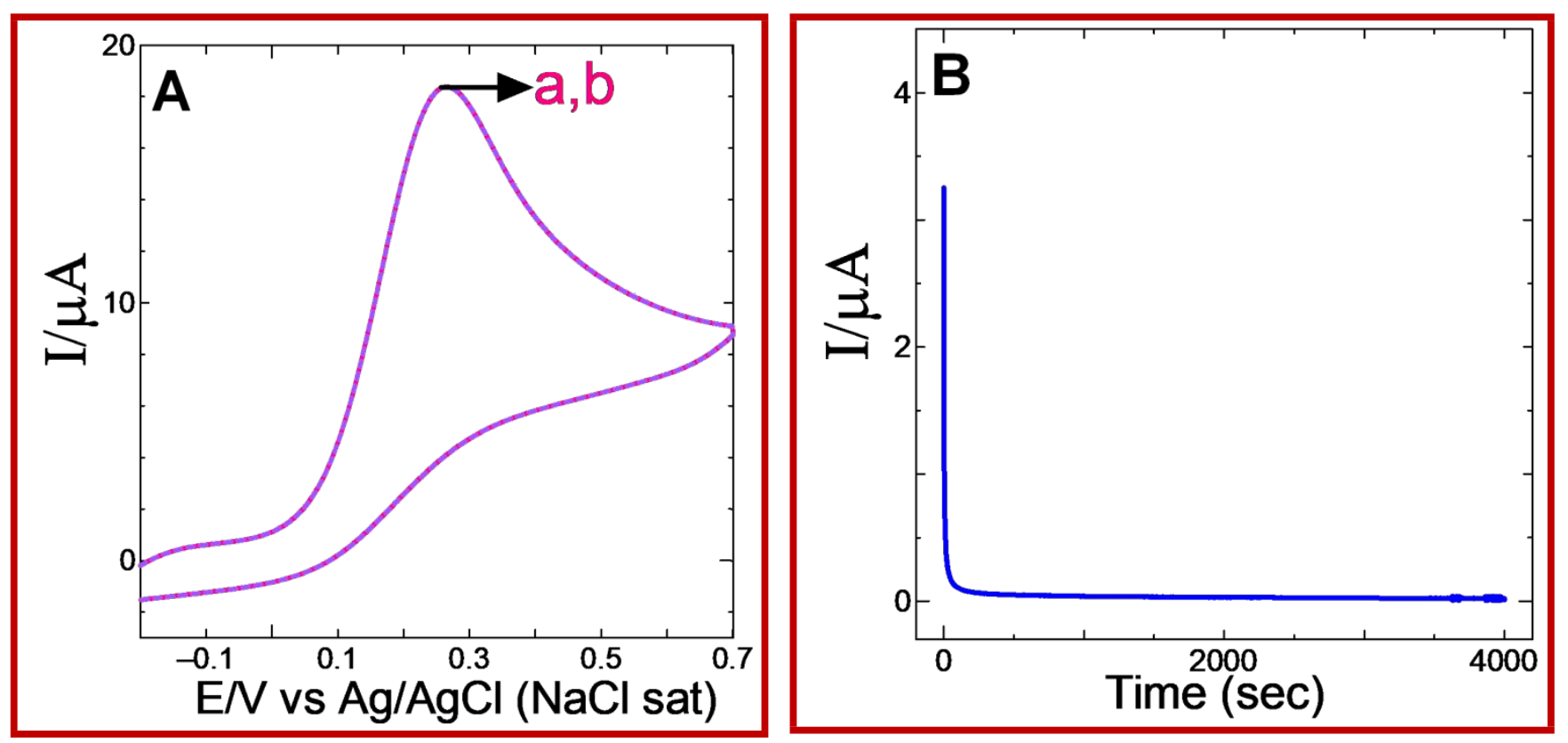

Figure S12. (A) CVs recorded for the oxidation of $1 \mathrm{mM}$ of AA at GC electrode modified with GCN (120 min exfoliation) in $0.2 \mathrm{M}$ PB solution $\mathrm{pH}$ (7.2) at different cycles after (a) $1^{\text {st }}$ and (b) $10^{\text {th }}$ cycles. (B) Chronoamperometric $i$ - $t$ curve for GC electrode modified with GCN (120 min exfoliation) in $0.2 \mathrm{M}$ PB solution ( $\mathrm{pH} 7.2)$. 


\begin{tabular}{|c|c|c|c|c|c|c|}
\hline \multicolumn{6}{|c|}{ Band positions $\left(\mathrm{cm}^{-1}\right)$} & \multirow{2}{*}{$\begin{array}{c}\text { Peak } \\
\text { assignments }\end{array}$} \\
\hline $\begin{array}{c}\text { GCN } \\
\text { powder }\end{array}$ & $\begin{array}{l}\text { GC/GCN } \\
\text { (15 min) }\end{array}$ & $\begin{array}{c}\text { GC/GCN } \\
(30 \mathrm{~min}\end{array}$ & $\begin{array}{c}\text { GC/GCN } \\
(60 \mathrm{~min})\end{array}$ & $\begin{array}{r}\text { GC/GCN } \\
(120 \text { min })\end{array}$ & $\begin{array}{l}\text { GC/GCN } \\
(180 \text { min })\end{array}$ & \\
\hline 3431 & 3172 & 3180 & 3172 & 3181 & 3182 & $\begin{array}{c}\mathrm{N}-\mathrm{H} \\
\text { stretching }\end{array}$ \\
\hline 1636,1574 & 1628,1566 & 1628,1566 & 1628,1566 & 1628,1566 & 1628,1566 & $\mathrm{C}=\mathrm{N}$ \\
\hline $\begin{array}{l}1461,1421, \\
1329,1252\end{array}$ & $\begin{array}{c}1455, \\
1320,1240\end{array}$ & $\begin{array}{c}1455,1320 \\
1240\end{array}$ & $\begin{array}{c}1455,1320 \\
1240\end{array}$ & $\begin{array}{c}1455, \\
1320,1240\end{array}$ & $\begin{array}{c}1455, \\
1320,1240\end{array}$ & $\mathrm{C}-\mathrm{N}$ \\
\hline 810 & 808 & 808 & 808 & 808 & 808 & $\begin{array}{l}\text { Breathing } \\
\text { mode of the } \\
\text { triazine unit }\end{array}$ \\
\hline
\end{tabular}

Table S1. FT-IR and ATR-FT-IR spectral data of powder GCN and GCN coated on GC plates with different exfoliation time. 


\begin{tabular}{|c|c|c|}
\hline \multicolumn{2}{|c|}{ Binding energy (eV) } & \multirow{2}{*}{ Peak assignments } \\
\hline GCN & GC/GCN & \\
\hline $\begin{array}{l}284.7 \\
288.4\end{array}$ & $\begin{array}{l}284.6 \\
288.3\end{array}$ & $\begin{array}{c}C \mathbf{1 s} \\
\mathrm{C}=\mathrm{C} \\
\mathrm{sp}^{3} \mathrm{C}=\mathrm{N}\end{array}$ \\
\hline $\begin{array}{l}398.5 \\
399.3 \\
400.3\end{array}$ & $\begin{array}{l}398.7 \\
399.5 \\
400.7\end{array}$ & $\begin{array}{c}\text { N 1s } \\
\mathrm{sp}^{2} \mathrm{C}=\mathrm{N}-\mathrm{C} \\
\mathrm{N}-(\mathrm{C})_{3} \\
\mathrm{C}-\mathrm{N}-\mathrm{H}\end{array}$ \\
\hline
\end{tabular}

Table S2. The XPS peaks for GCN powder and GCN coated on GC plate after exfoliation in water for $120 \mathrm{~min}$ and their assignments. 


\begin{tabular}{ccccc}
\hline Parameters & $\begin{array}{c}\text { Exfoliation time } \\
(\mathbf{m i n})\end{array}$ & EASA $\left(\mathbf{c m}^{\mathbf{2}}\right)$ & $\begin{array}{c}\mathbf{R}_{\mathbf{C T}} \\
(\mathbf{\Omega})\end{array}$ & $\begin{array}{c}\boldsymbol{k}_{\text {et }} \\
\left(\mathbf{1 0}^{-\mathbf{4}}\right)\end{array}$ \\
\hline Bare GC & - & 0.06 & 14916 & 2.3 \\
GC/GCN & 15 & 0.04 & 22370 & 1.7 \\
GC/GCN & 30 & 0.05 & 19524 & 1.8 \\
GC/GCN & 60 & 0.09 & 7092 & 5.5 \\
GC/GCN & 90 & 0.23 & 5010 & 7.6 \\
GC/GCN & 120 & 0.35 & 1816 & 20.9 \\
GC/GCN & 150 & 0.28 & 3248 & 11.7 \\
GC/GCN & 180 & 0.26 & 4988 & 7.6 \\
\hline
\end{tabular}

Table S3. The electroactive surface area, charge transfer resistance and heterogeneous electron transfer rate constant obtained for bare GC and GCN coated on GC electrode from different exfoliation time. 